\title{
ASPECTOS SOCIAIS E JURÍDICOS DA VIOLÊNCIA DOMÉSTICA CONTRA O HOMEM
}

\author{
SOCIAL AND LEGAL ASPECTS OF DOMESTIC VIOLENCE AGAINST MAN
}

\author{
Tiago Saraiva de Assis ${ }^{1}$
}

RESUMO: A violência doméstica é uma mazela social, presente, muitas vezes, silenciosamente, em diversos lares, causando danos irreparáveis em suas vítimas. Embora já haja avanços da lei nesse sentindo, o que podemos observar é a maneira como a vítima se comporta diante das agressões, na maioria das vezes não denunciando por vergonha de familiares, vizinhos ou até mesmo, por descrédito nas autoridades. Muito embora, em um primeiro momento, a expressão violência doméstica seja interpretada como violência contra a mulher, ela pode ser desferida contra qualquer pessoa, indiferente de gênero ou orientação sexual. Ocorre diferenciação na proteção estatal a direitos básicos, como direito à integridade física e à saúde, devido ao gênero? No presente trabalho será abordada a violência contra o homem, existente, em comparativo, na mesma proporção que a violência contra a mulher, porém pouco difundida e tratada como um tabu.

Palavras-chave: Legislação. Violência doméstica. Sociedade. Tabu social.

ABSTRACT: Domestic violence is a social problem, often present silently in several homes, causing irreparable damage to its victims. Although already there advances in the law in this sense, what we can observe is the way the victim behaves in the face of aggression, most of the time not denouncing it because of the shame of family members, neighbors or even, due to the authorities' discredit. Although, at first, the term domestic violence is interpreted as violence against women, it can be expressed against anyone, regardless of gender or sexual orientation. Occurs differentiation in the state protection of basic rights, such as the right to physical integrity and health, due to gender? In the present work, violence against men will be approached, existing, in comparison, in the same proportion as violence against women, however little widespread and treated as a taboo.

Keywords: Legislation. Domestic violence. Society. Social taboo.

\footnotetext{
I Graduado em Direito pela Universidade Federal de Campina Grande - UFCG. E-mail: tiagosaraiva7@hotmail.com.
} 


\section{INTRODUÇÃO}

A violência doméstica, em todos os sentidos, sempre foi tratada como um tabu, pois, normalmente, a vítima possui um forte vínculo afetivo com o agressor, o que inibe a denúncia. De outro norte, existe a dificuldade na identificação do crime pela sociedade, por utilizar, o agressor, da proteção do lar para encobrir seus delitos.

No ano de 2002, o Estado Brasileiro foi condenado por omissão e negligência pela corte Interamericana de Direitos Humanos, sendo obrigado a reformular suas leis e políticas em relação a violência doméstica.

Foi nesse diapasão que a legislação nacional, que, em seus primórdios, entendeu ser esse tipo de agressão apenas motivo de agravante genérica para lesão corporal, passou a tratar o fato de forma mais severa, acrescentando dois parágrafos ao art. 129 do Código Penal Brasileiro, passou assim a tipificar tal agressão como Violência Doméstica, com o advento da lei Io.886 de I7 de junho de 2004 .

No dia 7 de agosto de 2006, foi publicada a lei Ir.340, tratando sobre a violência doméstica e familiar contra a mulher, lei que ficou conhecida pelo nome de Maria da Penha em homenagem a cearense que passou boa parte da vida sofrendo e buscando justiça diante das barbáries praticadas por seu marido.

Porém, o direito é dinâmico, a lei não consegue contemplar os adventos da evolução social e acaba necessitando de adequações para se enquadrar à realidade.

$\mathrm{Na}$ sociedade atual a mulher tem um espaço que anteriormente não possuía, entrando em mercados de trabalho anteriormente vistos como sendo exclusivamente masculinos. São chefes de famílias, comandam lares e têm pessoas sob sua dependência econômica e domínio.

Esse movimento é chamado pela doutrina de novo conceito de família, diferente do conceito anteriormente tradicional, formado por um pai provedor, uma mãe doméstica e filhos.

Com maior concorrência no mercado de trabalho, desemprego crescente e outros motivos subjetivos, muitos homens se encontram em situação fragilizada diante de sua companheira, por vezes, submetendo-se a agressões psicológicas ou físicas, sem reclamar, por entender que a lei é mais severa em seu desfavor, afastando a isonomia, e temendo sanções, caso se defenda das agressões. Situação parecida ao que ocorria com a mulher em tempos passados, a pessoa agressora permanece impune e a vítima, oculta.

A denúncia, na maioria das vezes, acaba não acontecendo por vergonha, não apenas por estar diante de uma sociedade e de um estado machista, mas também da família e amigos, dado o preconceito existente, por ser o sexo masculino, aquele taxado como "o forte". 
Também no âmbito familiar a agressão sofrida por uma filha, seja ela feita pelo pai ou mãe, é tratada de maneira diferente do que a sofrida por um filho.

Se o primeiro caso é facilmente enquadrado como violência doméstica e incide na lei Maria da Penha, no segundo é dado tratamento diverso, quase sempre a situação é ignorada pelos que a conhecem, tratada como insignificante, aviltando-se o estado emocional do ser masculino e desvirtuando o princípio da isonomia contemplado no art. 5.. da Constituição Federal. Não se considera que em ambos os casos o agredido fica em estado de fragilidade diante do agressor, sendo dado pelo Estado tratamento distinto a agressões semelhantes.

Surgem, então, as indagações: A sensação de um ser masculino agredido por uma mulher deve ser ignorada ou diminuída, em relação à quando uma hipótese contrária ocorre? Porque o íntimo masculino pode ser agredido pelo ser feminino sem sanções, sendo que quando o contrário ocorre, o ser agressor é devidamente punido?

No aludido estudo, será abordada a Violência Doméstica no ordenamento brasileiro, a evolução da lei com punições mais severas contra os crimes realizados contra a mulher e a violência contra o homem.

Trar-se-á à discussão a existência ou não de tratamento isonômico quando a vítima é do sexo masculino.

\section{A violência doméstica na legislação brasileira}

A violência doméstica no Brasil está associada a agressões sofridas por mulheres, companheiras, esposas, namoradas, filhas, tendo sempre o homem como o agressor.

$\mathrm{Na}$ maioria das vezes em que se fala de violência doméstica, é culturalmente tácito que a vítima será uma mulher e o agressor, um homem.

$\mathrm{Na}$ sociedade brasileira, falar em violência doméstica é sinônimo de violência contra a mulher, é o que podemos observar em matéria veiculada a esse respeito encontrada em dados do Instituto Patrícia Galvão: ${ }^{2}$

No Brasil, estima-se que cinco mulheres são espancadas a cada 2 minutos; o parceiro (marido, namorado ou ex) é o responsável por mais de $80 \%$ dos casos reportados, segundo a pesquisa Mulheres Brasileiras nos Espaços Público e Privado (FPA/Sesc, 2010).

Apesar dos dados alarmantes, muitas vezes, essa gravidade não é devidamente reconhecida, graças a mecanismos históricos e culturais que geram e mantêm

\footnotetext{
${ }^{2}$ Disponível em:<https://dossies.agenciapatriciagalvao.org.br/violencia/violencias/violencia-domestica-efamiliar-contra-as-mulheres/> Acesso em: 26/03/2019.
} 
desigualdades entre homens e mulheres e alimentam um pacto de silêncio e conivência com estes crimes.

$\mathrm{Na}$ pesquisa Tolerância social à violência contra as mulheres (Ipea, 2014), 63\% dos entrevistados concordam, total ou parcialmente, que "casos de violência em casa devem ser discutidos somente entre os membros da família". E 89\% concordam que "a roupa suja deve ser lavada em casa", enquanto $82 \%$ consideram que "em briga de marido e mulher não se mete a colher".

$\mathrm{Na}$ mesma publicação podemos observar a explicação dada pelo autor ao responder o que é violência doméstica: ${ }^{3}$

\section{O que é a violência doméstica?}

Uma das imagens mais associadas à violência doméstica e familiar contra as mulheres é a de um homem - namorado, marido ou ex - que agride a parceira, motivado por um sentimento de posse sobre a vida e as escolhas daquela mulher. De fato, este roteiro é velho conhecido de quem atua atendendo mulheres em situação de violência: a agressão física e psicológica cometida por parceiros é a mais recorrente no Brasil e em muitos outros países, conforme apontam pesquisas recentes.

A recorrência, porém, não pode ser confundida com regra geral: a relação íntima de afeto prevista na Lei Maria da Penha (Lei n.ำ II.340/2006) não se restringe a relações amorosas e pode haver violência doméstica e familiar independentemente de parentesco - o agressor pode ser o padrasto/madrasta, sogro/a, cunhado/a ou agregados - desde que a vítima seja uma mulher, em qualquer idade ou classe social.

Nota-se que existe na definição citada a necessidade de que a vítima seja mulher, na contramão desse conceito observamos a colocação de Cavalcanti dando uma definição mais ampla sobre o assunto (2007, p. 33):

Violência, em seu significado mais frequente, quer dizer uso da força física, psicológica ou intelectual para obrigar outra pessoa a fazer algo que não está com vontade; é constranger, é tolher a liberdade, é incomodar, é impedir a outra pessoa de manifestar sua vontade, sob pena de viver gravemente ameaçada ou até mesmo ser espancada, lesionada ou morta. É um meio de coagir, de submeter outrem ao seu domínio, é uma forma de violação dos direitos essenciais do ser humano.

No artigo 226, § 8으, da Constituição Federal, consta que: "O Estado assegurará a assistência à família na pessoa de cada um dos que a integram, criando mecanismos para coibir a violência no âmbito de suas relações”. Contudo, quanto à sua abrangência, a Lei no 11.340/ 2006 destina-se tãosomente às mulheres em situação de violência, segundo o proferido no Art. I.o:

3 Disponível em:<https://dossies.agenciapatriciagalvao.org.br/violencia/violencias/violencia-domestica-efamiliar-contra-as-mulheres/> Acesso em: 26/03/2019. 
[...] esta Lei cria mecanismos para coibir e prevenir a violência doméstica e familiar contra a mulher, nos termos do § 8.. do artigo 226 da Constituição Federal, da Convenção sobre a Eliminação de Todas as Formas de Violência contra a Mulher, da Convenção Interamericana para Prevenir, Punir e Erradicar a Violência contra a Mulher e de outros tratados internacionais ratificados pela República Federativa do Brasil; dispõe sobre a criação dos Juizados de Violência Doméstica e Familiar contra a Mulher; e estabelece medidas de assistência e proteção às mulheres em situação de violência doméstica e familiar [...].

Embora, deveras, os fatos sejam alarmantes e significativos em violência sofrida por mulheres, em abstrato, não é essa a pretensão dada pelo legislador ao criar o instituto da violência doméstica, que é bem mais amplo do que a violência restrita à mulher.

No Brasil, a violência doméstica é historicamente tratada como violência de gênero, ou seja, não se considera o intuito do legislador em proteger a pessoa no âmbito familiar, independente do sexo, conforme afirmação feita por Mirabete (20II, p.82):

As normas relativas à violência doméstica previstas nos $\$ \S 9.9$ a II do art. I29 aplicam-se independentemente do sexo do ofendido. Tratando-se de violência doméstica e familiar contra a mulher, aplicam-se também as regras especiais

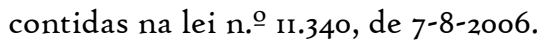

Existe uma linha teórica entre a Violência Doméstica geral e a Violência Doméstica contra a Mulher. Embora sejam institutos diferentes, observa-se, na sociedade brasileira, a mistificação de que toda a violência doméstica é sofrida por mulheres.

Já em países como Portugal, o tema é tratado em aspecto amplo, demonstrando ser a Violência Doméstica muito mais que agressões feitas em determinado gênero, conforme podemos observar em dados da APAV:4

\footnotetext{
A violência doméstica abarca comportamentos utilizados num relacionamento, por uma das partes, sobretudo para controlar a outra.

As pessoas envolvidas podem ser casadas ou não, ser do mesmo sexo ou não, viver juntas, separadas ou namorar.

Todos podemos ser vítimas de violência doméstica.

As vítimas podem ser ricas ou pobres, de qualquer idade, sexo, religião, cultura, grupo étnico, orientação sexual, formação ou estado civil.
}

A legislação brasileira tratava a violência doméstica como agravante genérica de lesão corporal, passando a tipificar como crime após condenação pela corte Interamericana de Direitos Humanos, no caso Maria da Penha, elevando a pena e tipificando também a violência doméstica

\footnotetext{
${ }^{4}$ Disponível em: $<$ https://apav.pt/vd/index.php/features2> Acesso em: 26/o3/2019
} 
contra a mulher, o que leva nossa sociedade a associar Violência Doméstica apenas a determinado gênero, conforme Alice Bianchini: ${ }^{5}$

Como bem esclarece Victoria Barreda[I], "o gênero pode ser definido como uma construção social e histórica de caráter relacional, configurada a partir das significações e da simbolização cultural de diferenças anatômicas entre homens e mulheres. [...] Implica o estabelecimento de relações, papeis e identidades ativamente construídas por sujeitos ao longo de suas vidas, em nossas sociedades, historicamente produzindo e reproduzindo relações de desigualdade social e de dominação/subordinação."

Essa distinção pode ser observada pela visão conservadora e patriarcal de que o homem se sobrepõe em detrimento da mulher na sociedade, não observada, no entanto, a amplitude do Instituto da Violência Doméstica aplicado à Lei, pelo legislador.

\section{A violência doméstica sofrida pelo homem}

A sociedade, de uma maneira geral ao ouvir a expressão "violência doméstica", logo traz à memória as agressões sofridas pela mulher, em sua maior parte, tendo seu marido ou companheiro como agressor. Mas será que apenas a mulher sofre violência doméstica? $\mathrm{O}$ homem, no que lhe concerne, pode estar em situação de vulnerabilidade na relação?

Embora a violência mais comum e difundida seja a sofrida pela mulher, a violência contra o homem também existe e é mais comum do que se pensa. Então, por que em um estado onde todos devem ser tratados de maneira igualitária, existem tratamentos diferentes para casos semelhantes?

Dados referentes ao Reino Unido apontam que apenas 5\% dos casos de violência doméstica sofrida pelos homens são computadas por dados oficiais. Apenas ıo\% das vítimas masculinas levam o caso de agressão às autoridades. Entre as principais razões estão o tabu e os temores advindos de uma cultura criada de expectativas sobre o homem ${ }^{6}$. Lá, contudo, ao contrário do Brasil, pelo menos existe o cômputo de dados oficiais pelo governo ou órgãos atuantes representativos da causa, mas ainda assim a procura de ajuda pelos homens ainda é mínima, dada a cultura machista mundial.

Os homens, vítimas dessa violência são relutantes em informar sobre o fato ou procurar ajuda.

\footnotetext{
5 Disponível em: <https://professoraalice.jusbrasil.com.br/artigos/3121516or/o-que-e-violencia-baseada-nogenero> Acesso em: 26/03/2019.

${ }^{6}$ Disponível em:< https://www.telegraph.co.uk/men/thinking-man/why-female-violence-against-men-issocietys-last-great-taboo/ >Acesso em: 12/04/2019.
} 
Se já existe dificuldade em identificar a violência causada contra a mulher, quiçá a sofrida pelo homem, onde a sociedade nunca o coloca na situação de vítima, sempre o direcionando, consciente ou inconscientemente, à condição de culpado.

No Brasil, nem sequer existem dados oficiais de violência doméstica contra homens, sendo que a população encontra dificuldades até em fazer uma denúncia. ${ }^{7}$

Não há estatísticas oficiais de violência doméstica contra os homens no país, e os poucos estudos realizados a respeito não têm a devida visibilidade. Diversos países buscam soluções para a violência conjugal, vez que violência não tem gênero, enquanto o Brasil segrega a população até mesmo na possibilidade de denúncias de violência doméstica, não sendo permitido ao homem ter voz, obrigando-o a conviver diariamente com essa invisibilidade.

A figura criada culturalmente sobre a mulher, de delicadeza e inofensividade, contribui para que a violência contra o homem permaneça oculta ou até mesmo vista como "inexistente" diante da sociedade. ${ }^{8}$

Culturalmente aceitam-se os atos de violência feminina com esculpo de que, em geral não são físicas, e caso seja, não são potencialmente danosas como as violências oferecidas pelo sexo masculino. Com a construção estereotipada da mulher e suas simbologias, tornou-se intrínseco acreditar na simpatia e receptividade feminina. A simbologia da mulher foi fabricada baseando-se exclusivamente na capacidade de gerar vida.

Ao longo da história criaram-se privilégios de sexo, denominados por Colett Parent de "proteção cavalheiresca”, algo que na atualidade já deve ser superado, pois, devido ao tratamento, criou responsabilidades penais discriminatórias, fato que impactou no aumento da violência no país, mesmo que os dados sejam omissos ou até mesmo manipulados.

O trato social impacta na forma como a vítima sente e lida com a violência, segundo Sara Próton: ${ }^{9}$
O stress diário decorrente de humilhações e agressões psicológicas e verbais, aliado a automedicação ou consumo exacerbado de substâncias prejudiciais ao organismo, potencializam o desequilíbrio emocional do homem.
O silêncio social retira a fala da vítima, que é obrigada a permanecer calada, por vergonha dos amigos, familiares e até mesmo de profissionais da saúde. Um ciclo que parece não ter fim e que fragiliza o agredido a ponto de ver o suicídio como única esperança de se libertar.

\footnotetext{
7 Disponível em: $<$ https://canalcienciascriminais.com.br/violencia-afetiva-contra-homens/>. Acesso em: or/o4/2019.

${ }^{8}$ Disponível em: $<$ https://canalcienciascriminais.com.br/violencia-afetiva-contra-homens/>. Acesso em: oI/o4/2019.

9 Disponível em:< https://canalcienciascriminais.com.br/violencia-afetiva-contra-homens/>. Acesso em: ol/o4/2019.
} 
Existe uma teoria, embora bastante controvertida, de que as mulheres cometem violência doméstica em uma frequência idêntica a dos homens, a qual tem sido denominada de "simetria entre os sexos", tendo sua primeira evidência computada no ano de $1975:^{10}$

A primeira evidência empírica de simetria entre os sexos foi apresentada em 1975, no Inquérito Nacional sobre Violência Familiar dos EUA, realizada por Murray R. Straus e Richard J. Gelles em uma amostra nacionalmente representativa de 2 I46 "famílias intactas". A pesquisa concluiu que II,6\% dos homens e $12 \%$ das mulheres tinham sofrido algum tipo de violência conjugal nos últimos doze meses, enquanto 4,6\% dos homens e 3,8\% das mulheres tinham sofrido violência conjugal "grave". Esses resultados inesperados levaram Suzanne K. Steinmetz a cunhar o polêmico termo 'síndrome do marido espancado', em 1977. Desde a publicação de Straus e Gelles, achados de outros pesquisadores em violência doméstica têm contestado se a simetria entre os sexos existe realmente.

Um dos fatores que geram a violência contra os homens, está atrelado à tradicional teoria feminista, que veem todas as relações sociais sob o prisma das relações entre os sexos, tendo em sua visão, neomarxista, que existem vantagens dos homens em detrimento das mulheres e que o abuso físico é cometido pelo homem para manter essa vantagem, por conseguinte, a violência praticada pela mulher é para autoproteção.

\section{A aplicação analógica da lei maria da penha: existência ou não de tratamento isonômico}

Deveras, a lei Maria da Penha tem por escopo a proteção contra a violência familiar baseada no gênero. Porém, o conceito de violência doméstica é muito mais amplo. É o que podemos observar no art. 5.. da lei Ir.340/2006:

Art. 5.‥ Para os efeitos desta Lei, configura violência doméstica e familiar contra a mulher qualquer ação ou omissão baseada no gênero que lhe cause morte, lesão, sofrimento físico, sexual ou psicológico e dano moral ou patrimonial:

I - no âmbito da unidade doméstica, compreendida como o espaço de convívio permanente de pessoas, com ou sem vínculo familiar, inclusive as esporadicamente agregadas;

II - no âmbito da família, compreendida como a comunidade formada por indivíduos que são ou se consideram aparentados, unidos por laços naturais, por afinidade ou por vontade expressa;

III - em qualquer relação íntima de afeto, na qual o agressor conviva ou tenha convivido com a ofendida, independentemente de coabitação.

Parágrafo único. As relações pessoais enunciadas neste artigo independem de orientação sexual.

\footnotetext{
ro Disponível em: <The gender paradigm in domestic violence research and theory: Part I -The conflict of theory and data» (PDF)>. Aggression and Violent Behavior. 10 (6):682. Acesso em: 10/o4/2019.
} 
Observa-se que o conceito de violência doméstica vai além de agressões desferidas pelo cônjuge em casa.

Em uma análise do inciso I, existe a configuração de um primeiro cenário para a violência familiar, onde a unidade doméstica deve ser compreendida como o espaço de convívio permanente de pessoas, independentemente de vínculo familiar ou genético, inclusive as esporadicamente agregadas, como hóspedes e empregadas domésticas, podendo-se, inclusive, incluir nesse rol, os visitantes perenes do local familiar, a exemplo dos amigos íntimos, conforme entendimento de Cardin: ${ }^{\text {II }}$

De fato, faz-se necessário que a mulher vítima de violência intrafamiliar não apenas esteja na casa de alguém no momento da agressão - local onde há relações domésticas entre terceiros -, mas esta deve necessariamente fazer parte dessa unidade doméstica.

Ademais, alguns autores incluem a figura das empregadas domésticas - desde haja um vínculo intenso com a família -, os curadores e tutores - independentemente de haver vínculo de parentesco entre esses e os respectivos curatelados e tutelados -, bem como, as sobrinhas, enteadas e irmãs unilaterais.

No inciso II do art. $5^{\circ}$, a lei estende o campo de proteção para a comunidade formada por indivíduos que são ou se consideram aparentados, unidos por laços naturais, por afinidade ou por vontade expressa, conforme Maria Berenice Dias (2006, p. 43 e 44):

Note-se que no conceito constituído acima, fala-se em "comunidade formada por indivíduos" e não em homem e mulher, dessa forma, não se restringe a família à união constituída pelo casamento.

Destarte, incluem-se nas considerações do inciso II, art. 5. ${ }^{\circ}$ da Lei Maria da Penha, os indivíduos unidos pela união estável, a família conhecida como anaparental formada por irmãos -, as famílias paralelas - em que o homem ou a mulher mantém duas famílias -, a família homossexual - tendo em vista o parágrafo único do citado artigo -, ou ainda, a entidade familiar formada por qualquer dos pais e seus descendentes (art. 226, § 4.ํㅡ, Constituição Federal).

Aqui prepondera o espírito do legislador que, ao aplicar para todos, sem distinção de tipo de vínculo, seja afetivo ou sanguíneo, nem obrigatoriedade de oficialização ou pré-reconhecimento estatal da união familiar, os princípios constitucionais da proteção à dignidade humana, à integridade física e moral, à saúde e à segurança jurídica, por meio da materialização deste dispositivo, acaba estendendo, felizmente, esta proteção, aos membros dos mais diversos tipos de união familiar, inclusive homens, em consonância com o entendimento do parágrafo único do Art. 5.ำ da Lei II.340/2006.

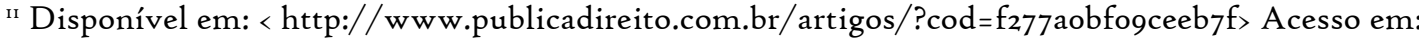
13/05/2019.
} 
O inciso 3. ${ }^{\circ}$ trata das relações íntimas de afeto, "sob esse prisma as relações entre namorados ou ex-namorados, bem como, entre noivos e ex-noivos será abrangida no rol de proteção da lei II.340/2006; salientando-se, porém, que a violência deve ter como causa a relação íntima de afeto". (Cardin, 2019).

A Constituição Federal, em seu artigo 5.ํㅡ, estabeleceu que todos são iguais perante a lei, sem distinção de qualquer natureza, mais adiante, institui que homens e mulheres são iguais em direitos e obrigações. Essa igualdade é fruto “de uma evolução histórica que está estreitamente vinculada às reações ao patriarcalismo, aos modos de produção e mais recentemente ao movimento feminista, que foi a revolução do século.” Pereira (2012, p. 164).

As medidas protetivas constantes na lei Maria da Penha, são mais amplas e mais completas do que as demais normas sobre violência doméstica elencadas no Código Penal. Consequentemente o homem vítima de violência doméstica, é injustiçado por não ser amparado pela lei, Natália Droichi de Almeida, utiliza o seguinte exemplo para demonstrar a questão. ${ }^{12}$

Um pai de família volta para casa transtornado e, como de hábito, encontra sua filha na sala, uma menina de ro anos e um garoto maior de idade, filho da empregada doméstica que trabalha na casa. $O$ pai decide por agredi-los sem nenhuma explicação. Na menina ele dá uma cintada na altura das costas e no rapaz ele produz graves queimaduras nas mãos, ao segurá-las sob frigideira em fogo alto". Segundo essa lei, por ter expressamente estabelecido que a violência deve ser proferida "contra a mulher", instituiria uma pena mais grave à violência proferida à menina, deixando-os em desigualdade, mesmo analisando, de acordo com esse caso, que a violência contra o jovem foi muito mais penosa.

Por conseguinte, não estender a aplicabilidade da lei Maria da Penha para os homens é o mesmo que negar os direitos humanos, ferir a Lei Maior, não garantindo isonomia em direitos e obrigações.

Como podemos observar, a lei coloca como polo passivo a mulher, fazendo configurar somente ela como vítima de violência no âmbito da unidade doméstica. Isso faz com que ocorra tratamento jurídico diverso, pois delimita a aplicação da lei. Bitencourt (20ı, p. I42.):

Não se pode deduzir que a mulher seja a única e exclusiva vítima potencial ou real de violência doméstica, familiar ou de relacionamento íntimo. Também o homem pode sê-lo, tanto empírica quanto normativamente, conforme, aliás, se depreende da redação do § 9.. do art. 129 do Código Penal, que não faz restrição a respeito das qualidades de gênero do sujeito passivo, o qual pode abranger ambos os sexos.

\footnotetext{
${ }^{12}$ Disponível em: <https://www.direitonet.com.br/artigos/exibir/66o7/Inconstitucionalidade-da-Lei-Mariada-Penha> Acesso em: II/o4/2019.
} 
Lima ainda entende ter sido a Lei Maria da Penha benéfica aos homens em situação de violência, ao aumentar a pena prevista para o crime de lesão corporal para três anos de detenção (artigo 129, § 9º, do Código Penal), sem ter feito qualquer distinção de gênero. Lima (2011, p. 269):

\begin{abstract}
Além disso, a Lei Maria da Penha não excluiu o homem do sistema de proteção dos direitos humanos, nem retirou sua dignidade humana. O homem continua protegido na esfera penal. A lei não criou crimes para tutelar unicamente a mulher como sujeito passivo, nem estabeleceu penas maiores para os crimes cometidos contra as mulheres. Os tipos penais que protegem a mulher são os mesmos que protegem o homem; a pena prevista para os crimes praticados contra elas é igual à prevista quando a vítima for um homem.
\end{abstract}

Para a doutrina, o homem pode perfeitamente figurar no polo passivo de uma violência doméstica, o que a lei delimita são as medidas de assistência e proteção, que em princípio são aplicadas apenas se a vítima for mulher.

O Brasil, como Estado Democrático de Direito, elenca no art. 5..$^{\circ}$ de sua Constituição a igualdade, sem distinção de gênero, artigo derivado da Declaração Universal dos Direitos Humanos.

\title{
Conclusões
}

A presente pesquisa, sucintamente, tratou de um tema que ainda é um tabu social no orbe nacional.

A violência doméstica assola muitos lares. Violência silenciosa, que causa vergonha, que humilha, que perturba a vítima, principalmente quando agredida por aquela pessoa que tanto ama, aquela que deveria proporcionar-lhe proteção, afeto e bom ânimo.

Em nenhum momento a pesquisa pretendeu entrar em confronto com os perturbadores números da violência doméstica sofrida pelas mulheres, apenas demonstrou que a violência contra o homem, seja ele heterossexual ou homossexual, ou de qualquer outra denominação dada pela sociedade, é existente e o tabu é muito maior quando comparado com a violência sofrida pelas mulheres.

O homem é criado para ser forte, “o chefe da família”, o "provedor”, aquele que levanta na madrugada para, sorrateiramente, no canto da cortina, observar, na escuridão da noite, um barulho que acontece do lado de fora de sua "fortaleza", pois ele representa "a proteção do lar". Esquece-se, com isso, que por trás do super-herói visto pelos filhos, existe um ser humano, algumas vezes cheio de incertezas, que pode sentir medo, que sente dor. 
Tentou-se demonstrar que uma proteção motivada pelo gênero, ainda que por motivo elevado, não deve ser regra em um país democrático de direito.

Todo acadêmico, desde o tenro começo de seu curso ouve e repete no decorrer de sua vida, as palavras exaradas no art. 5.- , todos são iguais perante a lei, sem distinção de qualquer natureza [...], então como explicar essa igualdade, com uma distinção legal de gênero?

Sabe-se que, para existir a igualdade, muitas vezes se deve tratar de forma "desigual os desiguais”, atendendo ao princípio da igualdade material, porém, a diferenciação de um casal tradicional para um casal de homossexuais, por exemplo, absolutamente não se encaixa nesta tese.

Embora, ainda que minimamente, quando comparada à forma de vida do recente século passado, ainda vivamos numa sociedade patriarcal, as mulheres conquistaram muitos direitos. Muitas delas ganham muito mais financeiramente que seus maridos, chefiam famílias, têm direitos e deveres que antes eram tidos como exclusivamente dos homens.

O homem, em muitos lares, se encontra em situação vulnerável, suscetível as agressões e, quando por exceção busca auxílio, esbarra na falta de preparo do Estado, nas deficitárias leis que o punem, mas não o protegem.

As opiniões sobre o tema estão mudando, em maior escala mundial do que nacional, mas já existe entendimento que as leis devem se adaptar às evoluções sociais, pois engessar o direito e condicionar o magistrado a julgar baseado simplesmente na letra pura da lei pode causar grandes injustiças.

O tema é muito relevante e vai além da esfera penal, pois envolve família, sentimentos, relações conjugais, algo muito complexo para ser pura e simplesmente analisado sob a ótica de um dispositivo do Código Penal.

O homem agredido não é apenas vítima do seu agressor. Ele se torna vítima dos tabus sociais. Como exemplo, pode-se citar o caso do homem homossexual que prefere viver uma relação violenta, a ter sua orientação sexual revelada a familiares e pessoas de seu convívio geral. Muitas vezes, a dor do preconceito é maior que a dor das lesões causadas pela violência física que sofreu.

Ademais, importante frisar que, em muitos casos, o marido que bate na esposa foi o menino que era espancado pelo pai ou pela mãe, que aprendeu que a vontade é imposta pela força, que tudo se resolve na base da violência física. Contudo, sabemos que violência gera violência e, novamente insistindo na colocação, o problema não é apenas penal.

É, sobretudo, uma questão de reeducação, de reconstrução da cultura. E também questão de compreender que aquele ser humano violento não nasceu daquela forma. Ele é fruto de sua convivência, de seu aprendizado desde a infância. Somos produto do meio onde vivemos. Somos 
reflexo de nossos pais, amigos e familiares. Daí a importância da abertura da mente para uma conscientização universal das necessidades emocionais do homem, que sempre foram ignoradas e menosprezadas.

É necessária uma mudança cultural na sociedade, olhar para o seu semelhante e enxergar o ser humano que ele é, com suas necessidades e aflições, independentemente de ser homem ou mulher.

\section{Referências Bibliográficas}

APAV. Violência Doméstica. Fonte: APAV. pt: disponível em: https://apav.pt/vd/index.php/features2. Acesso em II abr. 2019.

ÁVILA, Thiago André Pierobom de. Lei Maria da Penha. Uma análise dos novos instrumentos de proteção às mulheres. Fonte: Projeto BuscaLegis 2007: Disponível em: http://www.egov.ufsc.br/portal/sites/default/files/anexos/13477-13478-I-PB.pdf. Acesso em I8 mai. 2019.

BEZERRA, Juliana. Lei Maria da Penha. Fonte: todamatéria: Disponível em: https://www.todamateria.com.br/lei-maria-da-penha/. Acesso em: 28 mar. 2019.

BIANCHINI, Alice. O que é violência "baseada no gênero". Fonte: Jusbrasil: Disponível em: https://professoraalice.jusbrasil.com.br/artigos/3121516or/o-que-e-violencia-baseadano-genero. Acesso em 26 mar. 2019.

BITENCOURT, Cezar Roberto.Tratado de direito penal: parte especial. ed. 23. São Paulo: Saraiva, 2008.

CAPEZ, Fernando. Curso de Direito Penal vol 2. ed.r4. São Paulo: Saraiva, 2014.

CAVALCANTI, Stela Valéria Soares Faria. Violência Doméstica: Análise da Lei "Maria da Penha", № 11.340/o6. ed. 3. Salvador: Jus Podium, 2007.

DAUBNEY, Martin. Why female violence against men is society's last great taboo. Fonte: The Telegraph: Disponível em: https://www.telegraph.co.uk/men/thinking-man/whyfemale-violence-against-men-is-societys-last-great-taboo/. Acesso em: II abr. 2019.

Dias, Maria Berenice. A lei Maria da Penha na justiça: a efetividade da lei 1r.340/2006 de combate à violência doméstica e familiar contra a mulher. Revista dos Tribunais, 2008. pp. 43-44.

MIRABETE, Julio Fabbrini. Manual de Direito Penal. ed. 32. São Paulo: Atlas S.A, 2011.

GALVÃO, Instituto Patrícia. Violência Doméstica e Familiar. Fonte: dossies.agenciapatriciagalvao.org.br: Disponível em: 
https://dossies.agenciapatriciagalvao.org.br/violencia/violencias/violencia-domestica-efamiliar-contra-as-mulheres/. Acesso em 26 mar. 2019.

GOMES, Luiz Flávio. Violência "machista" da mulher e Lei Maria da Penha: a mulher bate em homem e em outra mulher. Fonte: lfg.com: Disponível em: http://www.lfg.com.br. Acesso em ir abr. 2019.

IQBAL, Nomia.'Tinha medo do que iam pensar de mim', diz homem vítima de violência doméstica. Fonte: bbc.com: Disponível em: https://www.bbc.com/portuguese/noticias/2014/12/I41213_homem_violencia_domestica_ni _cc. Acesso em ir abr. 2019.

JESUS, Damásio de. Direito Penal parte especial 2ำ volume. ed. 29. São Paulo: Saraiva, 2009. JURIDICO, R. C. Lei Maria da Penha é aplicada para proteger homem. Fonte: Conjur.com: Disponível em: https://www.conjur.com.br/2008-out30/lei_maria_penha_aplicada_proteger_homem. Acesso em II abr. 2019.

LAVIGNE, Rosane Reis. PERLINGEIRO, Cecília. Das medidas protetivas de urgência artigos 18 a 21. In: CAMPOS, Carmen Heins. (Org.). Lei Maria da Penha comentada em uma perspectiva jurídicofeminista. Rio de Janeiro: Editora Lumen Juris, 20II. p. 289-306.

LETTIERE, Angelina. NAKANO Ana Márcia Spanó. Violência doméstica: as possibilidades e os limites de enfrentamento. Fonte: Rev. Latino-Am. Enfermagem [Internet]. 20I: Disponível em: http://www.scielo.br/pdf/rlae/vign6/pt_2o.pdf. Acesso em: 17 mai. 2019 .

PEREIRA, Rodrigo da Cunha. Princípios fundamentais norteadores do direito de familia. ed. 2. São Paulo: Saraiva, 2012.

PRÓTON, Sara. O masculino no direito brasileiro. livro digital, 20II, disponível em: http://www.bookess.com/read/30788-o-masculino-no-direito-brasileiro/. Acesso em 03 mai. 2019.

PRÓTON, Sara. O silêncio social e jurídico na violência afetiva contra os homens. Fonte: canalcienciascriminais.com: https://canalcienciascriminais.com.br/violencia-afetiva-contra-homens/. Acesso em or mai. de 2019 . 